Article

\title{
Thermogravimetric Kinetic Study of Automobile Shredder Residue (ASR) Pyrolysis
}

\author{
Soyoung Han ${ }^{1,2} \mathbb{D}$, Yong-Chul Jang ${ }^{2}$, Yeon-Seok Choi ${ }^{1, *}$ and Sang-Kyu Choi ${ }^{1}$ \\ 1 Korea Institute Machinery \& Materials, Daejeon 34103, Korea; syhan@kimm.re.kr (S.H.); \\ skchoi4091@kimm.re.kr (S.-K.C.) \\ 2 Department of Environmental Engineering, Chungnam National University, Daejeon 34134, Korea; \\ gogator@cnu.ac.kr \\ * Correspondence: yschoi@kimm.re.kr
}

Received: 8 February 2020; Accepted: 18 March 2020; Published: 20 March 2020

\begin{abstract}
The separated and sorted combustibles from automobile shredder residue (ASR) can be pyrolyzed and used as a heat source or liquefied to produce materials with added value. In this study, the thermal decomposition properties of ASR were determined and thermal kinetic studies were performed. Four types of raw materials were separated from ASR and mixed at a constant ratio: $38.5 \mathrm{wt} . \%$ of plastic; $31.6 \mathrm{wt} . \%$ of fiber; $17.3 \mathrm{wt} . \%$ of sponge; and $12.3 \mathrm{wt} . \%$ of rubber. Pyrolysis kinetics analysis was carried out using the Thermogravimetric analysis-derivative thermogravimetry (TGA-DTG) technique and activation energy were calculated by differential and integral isoconversional model methods, Flynn-Wall-Ozawa (FWO), Kissinger-Akahira-Sunose (KAS), and Friedman. Thermogravimetric analysis was performed under nitrogen with four temperature rate conditions from room temperature to $800^{\circ} \mathrm{C}$. In the thermal degradation profile, peaks representing mass loss rates were observed for each sample at different temperature ranges. It was observed that the final mass reduction temperature in the mixed samples was lower than in the individual samples. The activation energies of plastics and rubbers were $105.39 \mathrm{~kJ} / \mathrm{mol}$ and $115.20 \mathrm{~kJ} / \mathrm{mol}$ respectively. The sponge foams and fibers were $172.59 \mathrm{~kJ} / \mathrm{mol}$ and $160.30 \mathrm{~kJ} / \mathrm{mol}$ respectively. The mixed sample had an activation energy value of $159.56 \mathrm{~kJ} / \mathrm{mol}$. The basic physicochemical and pyrolysis characteristics of ASR were examined to be used as basic data for the recycling of ASR for future pyrolysis.
\end{abstract}

Keywords: ASR (Automobile Shredder Residue), thermogravimetiric analysis; thermal kinetic analysis; isoconversional method

\section{Introduction}

With the improvement of standards of living, the domestic market in Korea has expanded, and as of December 2018 the number of automobile registrations reached over 23 million [1]. As a result, the number of scrapped cars has increased steadily, and in 2018, about 890,000 scrapped cars were generated. About 100,000 of them are exported as used cars, most of which are dismantled and subject to recycling. In the demolition process of a scrapped vehicle, it is delivered to the first demolition company, and after useful parts are recovered, it is compressed and transferred to a shredder company [2]. After the shredder process for recovering valuable metals such as ferrous and nonferrous metals from the press body, residues such as synthetic resin, glass, and rubber, which are difficult to reuse, remain. Such residues are called automobile shredder residue (ASR). ASR, which typically accounts for about $25 \%$ of the car's weight, consists of $33 \%$ plastic, $32 \%$ fiber and sponge, $10 \%$ rubber, $4 \%$ metal, $4 \%$ glass and wood, and $17 \%$ soil and other [3]. These ASR have a lower recycling rate than metals and do not have a related technology or treatment base. Most of them are processed by simple incineration or landfill. Solid industrial wastes are generally incinerated and landfilled, but incineration 
or landfilling of ASR causes a reduction in the recycling rate of waste vehicles, a shortage of landfills, and environmental pollution. Therefore, technology development for recycling is required. In addition, strong regulations have been enacted and implemented to achieve a 95\% recycling rate for used vehicles in Europe. Korea also regulates the recycling at a rate of more than $95 \%$, according to the trend of advanced countries. Therefore, it is essential to increase the recycling rate of ASR, which accounts for $25 \%$ of the weight of used vehicles. For active recycling of ASR, it is important to sort out various combustible materials remaining in the residue. In fact, there have been many studies on the effective physical screening of automobile waste residues, mainly for material recycling. These have mainly been process studies to recover valuable metals from ASR [4-9]. In Korea, high-efficiency complex screening technology has been studied that can separate metals, FLUFF (very light weight waste), and PVC (polyvinylchloride) plastics by more than $90 \%$ and $95 \%$, respectively [3]. The separated and sorted combustible materials can be subjected to pyrolysis gasification and used as a heat source, or liquefied to produce materials with added value [10-14]. In this regard, the thermal decomposition properties of ASR have been provided in several previous studies and papers. Day et al. (1995) investigated the thermal decomposition characteristics of these materials with metal foreign substances by separating the flammable materials such as PP (polypropylene), ABS (acrylonitrile butadiene styrene copolymer), PU (polyurethane), and PVC from ASR and comparing them with those of pure materials [15]. The contamination of certain metals acted as a thermal decomposition catalyst in the thermal decomposition of plastics in ASR. Donaji et al. (2009) analyzed the pyrolysis kinetics of char remaining after ASR was pyrolyzed [16]. Haydary et al. (2016) and Mayyas et al. (2016) conducted studies to obtain the product of gaseous, liquid, and solid material from ASR by pyrolysis and to obtain solid phase valuables from ASR through thermal melting. These studies also treat ASR by pyrolysis, but are not the result of separate and sorting ASR study [17,18]. There are many general studies on the recycling of ASR, but there are not many studies on the pyrolysis kinetics of ASR which are highly polluted. The existing studies on the thermal decomposition kinetics analysis of municipal solid wastes and waste plastics or biomass were referred to as ASR [19-22] in this study. In this study, we screened many combustible materials included in ASR as main constituents, and then examined the pyrolysis characteristics of each mixed material and analyzed the dynamic values of each mixture by observing the pyrolysis characteristics of the mixed materials. It is well known that ASR, with its good separation, can be a good source of energy. Separation and sorting of ASR, consisting of a low degree of combustible materials, are very difficult in terms of cost and effort. At present, few works have studied the thermal properties of combustibles by separating the actual ASR according to our references. The whole world has turned away from simple landfills or incineration, making recycling of materials very important. In this regard, this study of sorted ASR's combustibles may serve as an important reference for further combustible waste recycling. This could be used as a supplementary theoretical basis for the facility in the future when it is intended to thermally recycle, away from simple incineration or landfilling of ASR or other low degree combustible materials.

\section{Materials and Methods}

\subsection{Materials}

According to automobile shredder residue (ASR) data gathered from the 2016 Korea Ministry of Environment's waste car treatment protocols, domestic ASR is composed of $74.45 \%$ of combustible components, which is composed of $28.7 \%$ plastic, $12.9 \%$ sponge, $23.6 \%$ fiber, and $9.2 \%$ rubber [3]. Therefore, based on this data, this study used $100 \%$ of combustible materials to calculate the composition ratio of plastics, sponges, fibers, and rubbers, and used them as mixed samples. The ASR sample collection procedure followed the domestic waste standard test method. ASR taken from J company (A shredder company) in Chungbuk Province of South Korea was separated into a mixture of four flammable materials: sponge foam, plastic, fiber, and rubber. The samples used in the experiment were five samples of each of the separated four types of raw materials collected and mixed ASR samples 
mixed at a constant ratio: $38.5 \mathrm{wt} . \%$ of plastic, $31.6 \mathrm{wt} . \%$ of fiber, $17.3 \mathrm{wt.} \%$ of sponge and $12.3 \mathrm{wt} . \%$ of rubber. The samples were dried in a dryer (over $8 \mathrm{hrs}$ under $105^{\circ} \mathrm{C}$ ) and ground to particles of $1 \mathrm{~mm}$ or less (IKA, MF10 basic) and used in basic properties measurements and TGA analysis experiments. Analysis of the basic properties of mixture ASR and separated ASR were carried out using proximate analysis (LECO, TGA701), elemental analysis (Thermo., Flash EA 1112) and calorific value measurement (LECO, $600 \mathrm{~A}$ ). The physical characteristics of ASR used in the present experiment are shown in Table 1.

Table 1. Comparison of physical characteristics of separated automobile shredded residue (ASR).

\begin{tabular}{ccccccc}
\hline $\begin{array}{c}\text { Physical Properties } \\
\text { (Dry Basis) }\end{array}$ & & $\begin{array}{c}\text { Mixed } \\
\text { ASR }\end{array}$ & $\begin{array}{c}\text { Sponge } \\
\text { Foam }\end{array}$ & Plastic & Fiber & Rubber \\
\hline Volatile (wt.\%) & & 79.16 & 83.09 & 90.52 & 70.61 & 62.03 \\
Fixed carbon (wt.\%) & & 7.94 & 6.36 & 0.96 & 10.40 & 20.09 \\
Ash (wt.\%) & & 12.90 & 9.93 & 8.51 & 18.05 & 17.86 \\
Element (wt.\%) & $\mathrm{C}$ & 63.05 & 60.3 & 75.6 & 49.46 & 67.05 \\
& $\mathrm{H}$ & 8.21 & 7.93 & 10.34 & 5.00 & 7.09 \\
& $\mathrm{O}$ & 13.58 & 17.16 & 4.3 & 25.85 & 6.94 \\
& $\mathrm{~N}$ & 1.87 & 4.31 & 0.97 & 1.31 & 0.52 \\
& $\mathrm{~S}$ & 0.08 & 0.04 & 0.08 & 0.11 & 0.19 \\
& $\mathrm{Cl}$ & 0.31 & 0.33 & 0.20 & 0.22 & 0.35 \\
$\mathrm{HHV}(\mathrm{cal} / \mathrm{g})$ & & 6970 & 6680 & 8930 & 5110 & 7230 \\
\hline
\end{tabular}

${ }^{1}$ By difference.

\subsection{Thermogravimetry Analysis Procedure}

Pyrolysis experiments were performed in a thermogravimetric analyzer (Shimadzu, DTG-60 AH), that could characterize the mass loss of a sample with time and temperature during a continuous heating process. Approximately $4 \mathrm{mg}$ to $6 \mathrm{mg}$ of sample was loaded into an alumina crucible for each experiment. High-purity nitrogen (99.99\%) with $50 \mathrm{ml} / \mathrm{min}$ was supplied to prevent sample combustion and to keep steady pyrolysis. The temperature was programmed for running at a range from $25^{\circ} \mathrm{C}$ to $800^{\circ} \mathrm{C}$ and set up at heating rates of $5^{\circ} \mathrm{C} / \mathrm{min}, 10^{\circ} \mathrm{C} / \mathrm{min}, 20^{\circ} \mathrm{C} / \mathrm{min}$, and $30^{\circ} \mathrm{C} / \mathrm{min}$.

\subsection{Kinetic Theory}

The main focus of this study was the use of mathematical model equations to determine the pyrolysis kinetics parameters of the feedstock. The basic equation of the rate of thermochemical conversion in the kinetic theory is usually described as:

$$
\frac{d \alpha}{d t}=k(T) f(\alpha)
$$

where, $\alpha$ : the degree of conversion, $t$ : time, $k(T)$ : the reaction rate constant, and $f(\alpha)$ : the reaction mechanism function, $f(\alpha)=(1-\alpha)^{n}$

The conversion $\alpha$ is defined as:

$$
\alpha=\frac{X o-X \tau}{X o-X f}
$$

where, $X_{0}$ : the mass of initial sample, $X_{\Gamma}$ : the sample mass at time $\tau$, and $X_{f}$ : the final mass after pyrolysis.

The variable $k$ is the reaction rate constant and is generally temperature dependent by the Arrhenius equation.

$$
k=A e^{-E / R T}
$$

where, $A$ : the pre-exponential factor (frequency factor), $E$ : the activation energy, $R$ : the universal gas constant and $T$ : the absolute temperature. 
In order to calculate kinetic parameters based on results acquired from TGA, by combining Equations (1) and (3), a fundamental analytical equation is obtained:

$$
\frac{d \alpha}{d t}=A f(\alpha) e^{-E / R T}
$$

Assuming that the heating rate is defined as $\beta=d T / d t$, the Equation (4) can be written as:

$$
\frac{d \alpha}{d T}=\frac{A}{\beta} f(\alpha) e^{-E / R T}
$$

Estimation of kinetic parameters, such as the pre-exponential factor $(A)$ and the activation energy $(E)$, which are based on the kinetic theory and TGA data, can be made by different techniques. These techniques are known as model-fitting (which could include identification of the kinetic reaction model) or model-free (i.e., isoconversional). The model fitting approach is widely used for both isothermal and non-isothermal data, but the kinetic parameters are determined by $f(\alpha)$, in other words, how to assume the shape of the reaction model. In the non-isothermal experiments, since $\mathrm{T}$ and $\alpha$ change simultaneously, the model fitting method makes it difficult to clearly distinguish between the temperature-dependent $k(T)$ and the reaction model $f(\alpha)$, which is uncertain. These values cannot be compared significantly with those obtained by isothermal measurements and cannot be used to reasonably predict isothermal kinetics. The model-free approach, expressed using the isothermal method, determines the activation energy as a function of conversion and temperature for isothermal and non-isothermal experiments without any assumptions about the reaction model, and can offer consistent kinetic parameters [23].

\subsection{Model-Free Methods}

The Friedman method is the most common differential isoconversional method, and it is usually described by the following equation [24]:

$$
\frac{d \alpha}{d t}=\beta \frac{d \alpha}{d T}=A f(\alpha) e^{-E / R T}
$$

It has to be noted that the analysis does not provide the knowledge of the reaction model. The Friedman method uses the natural logarithm of the reaction conversion rate as a function of its corresponding temperature at different conversion rates, which is obtained by simple rearrangement of Equation (6):

$$
\ln \left(\frac{d \alpha}{d t}\right)=\ln \left[\beta\left(\frac{d \alpha}{d T}\right)\right]=\ln [A f(\alpha)]-\frac{E}{R T}
$$

Equation (7) is plotted in straight lines as $\ln (d \alpha / d t)$ or $\ln [\beta(d \alpha / d T]$ vs. $1 / T$. The slope is $-E / R$ and the constant term is $\ln [A f(\alpha)]$. It indicates that the reaction conversion depends on the rate of mass reduction by the reaction regardless of the temperature [13].

The Flynn-Wall-Ozawa (FWO) method, together with the Freidman method, are the most widely used isoconversional methods for determining activation energy, $E$. In the FWO method, assuming that $A, \alpha$, and $E$ are independent of temperature, Doyle's approximation is applied to $P(u)$ by integrating Equation (4) into Equation (8). This method takes advantage of the correlation between different heating rates, activation energies, $\mathrm{E}$ and temperature. In this method, the activation energy, $E$ is determined from the Equation $(8)[25,26]$ :

$$
\mathrm{g}(\alpha)=\int_{0}^{\alpha} \frac{d \alpha}{f(\alpha)}=\frac{A}{\beta} \int_{0}^{T} \exp \left(-\frac{E}{R T}\right) d T=\frac{A E}{\beta R} P(u)
$$


Equation (9) was taken the natural log in Equation (8) and arranged.

$$
\operatorname{lng}(\alpha)=\ln \left(\frac{A E}{R}\right)-\ln \beta+\ln P(u)
$$
$1.052 \frac{E}{R T}$.

Equation (10) was summarized Equation (9) using Doyle's approximation, $\ln P(u) \cong-5.331-$

$$
\ln \beta=\ln \left(\frac{A E}{R g(\alpha)}\right)-5.331-1.052 \frac{E}{R T}
$$

With the assumption that $\beta$, heating rate has a fixed value, E can be obtained from the slope of the straight line from plotting $\ln \beta$ against $1 / \mathrm{T}$ for a variety of degrees of conversion [27].

The Kissinger-Akahira-Sunose (KAS) method is an integral isoconversional technique, as is the FWO method. In Equation (9) Doyle's approximation, $\ln P(u) \cong \frac{e^{-u}}{u^{2}}$, was used to be replaced and summarized as the following equation, Equation (11). The fundamental expression for calculation of the activation energy by this method is [28]:

$$
\ln \left(\frac{\beta}{T^{2}}\right)=\ln \left(\frac{A R}{E g(\alpha)}\right)-\frac{E}{R T}
$$

By plotting $\ln \left(\beta / T^{2}\right)$ vs. $1 / T$ for constant $\alpha$, straight lines are obtained, which slopes are used for evaluation of the activation energy. Since determination of the frequency factor for model-free methods requires the assumption of the reaction model $f(\alpha)$, in this paper, it is assumed to take the following form:

$$
f(\alpha)=(1-\alpha)^{2}
$$

Meanwhile, the pre-exponential factor was determined for order of reaction $n=2$ [29].

\section{Results and Discussion}

\subsection{Physical Analysis and TGA Results}

Proximate analysis and element analysis result of the five samples of ASR are shown in Table 1. All samples used in the experiment were conditioned on a dry basis. High heating value of the samples showed from $5110 \mathrm{cal} / \mathrm{g}$ of fiber to $8930 \mathrm{cal} / \mathrm{g}$ of plastic and ash content presented from $8.51 \mathrm{wt} . \%$ of plastic to $18.05 \mathrm{wt}$.\% of fiber, slightly higher value that could be originated from an impurity as soils and metals. In Hyun Tae Joung et al.'s study, the raw material ASR of Korea, including both combustibles and non-combustibles, was classified into about 11 types, and ash and calorific value were measured [30]. The ash content of light fluff of ASR with $19.6 \mathrm{wt} . \%$ was similar to Fiber in Table 1. The calorific value of plastics, $9086 \mathrm{cal} / \mathrm{g}$ was similar to the plastic of Table 1 . Other sponges, fibers, and rubbers were $4532 \mathrm{cal} / \mathrm{g}$, $4073 \mathrm{cal} / \mathrm{g}$, and $5526 \mathrm{cal} / \mathrm{g}$, which were about $2000 \mathrm{cal} / \mathrm{g}$ lower than those of Table 1. It was highly likely that ASR itself was contaminated with non-combustible materials, and the difference in calorific value was also observed. In addition, there may be a reason for the increase of parts made of high molecular polymer compounds in automobile interior materials currently.

In order to obtain kinetic parameter determination, a TGA analyzer was used. The data are presented on the following figures as sample conversion $(1-\alpha)$ and mass change rate $(\mathrm{d} \alpha / \mathrm{d} t)$ as a function of temperature $(T)$. Figure 1 shows the TGA results in the order of sponge foam, plastic, fiber, rubber, and mixed ASR. The figure shows the results of the experiment according to the heating rate with the horizontal axis as the temperature. The blue line shows the tendency of mass to decrease with increasing temperature in all samples. The mass change rate values, represented by the red line, represent peaks at specific temperatures, indicating that thermochemical conversion occurs under a nitrogen atmosphere and a rapid change in mass of the sample occurs. In addition, it can be seen that peaks are formed at different temperature ranges according to the types of samples. The sponge foams and plastic showed rapid degradation around $400{ }^{\circ} \mathrm{C}$, while the other samples, rubber and 
fiber, showed graphs of mass loss with a relatively gentle slope. Even in the mass loss rate peak of the red line, foam and plastic have a single maximum peak. Fiber and rubber show about three peaks depending on the temperature. This means foam and plastic have simpler compounds than fiber and rubber. The mixed sample of these four materials graph, Figure 1e shows a major mass reduction peak up to near $480^{\circ} \mathrm{C}$ and a gentle mass loss rate peak up to around $725^{\circ} \mathrm{C}$ again. The shape of the mixed sample graph looks similar to the superimposed graph of the other four materials. In Figure 1, it can be observed that as the heating rate increases, the mass reduction rate of the reactant to the temperature is skewed to the right. At the same time, the peak of the red graph showing the rate of mass change shows a right bias as the heating rate rises. This is a common phenomenon in research that investigates the thermal decomposition of polymers. This is known to be due to the difference in the activation energy of the reactants [31]. The change of mass loss ratio and mass change rate with the temperature of mixed ASR is shown in Figure 1e. This curve trend is shown to be similar to the graph trends of plastics and fibers, which make up a large proportion of the mixed ASR.

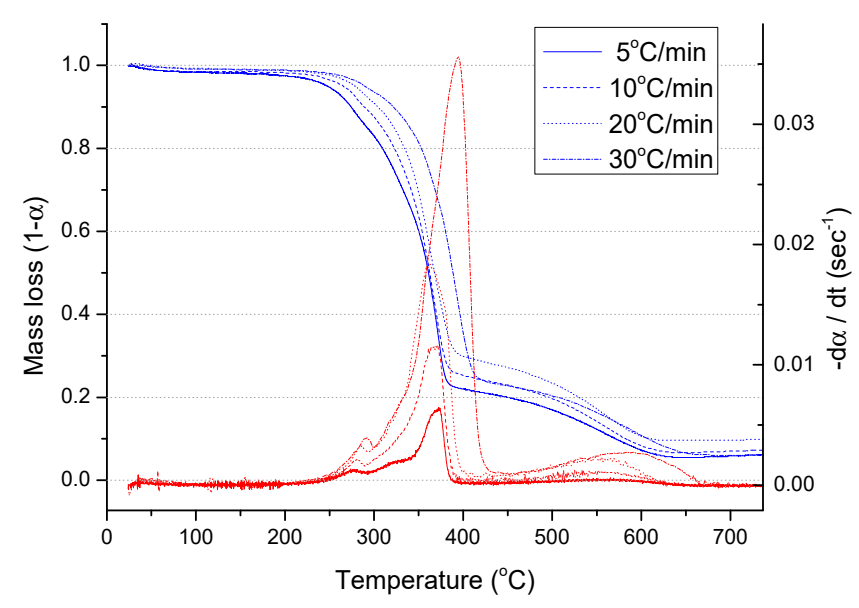

(a)

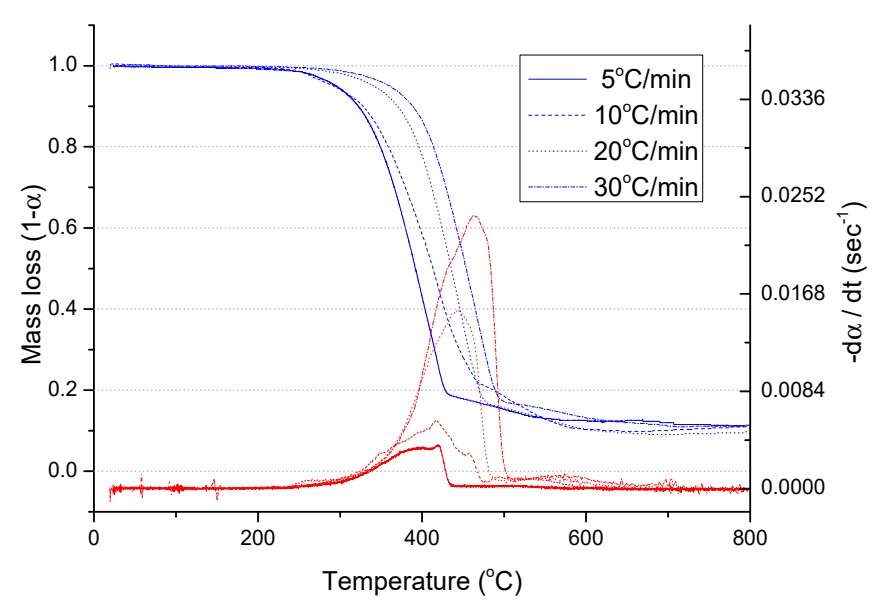

(b)

Figure 1. Cont. 


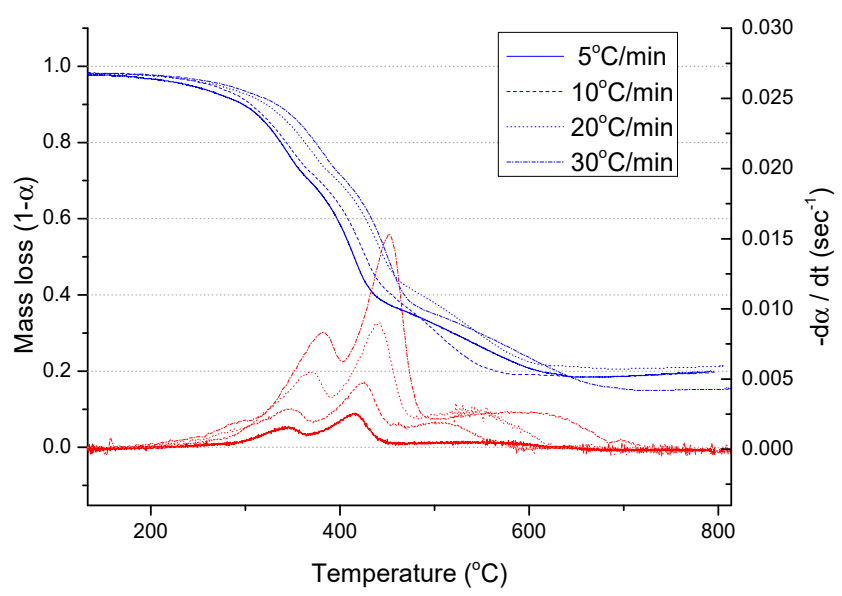

(c)

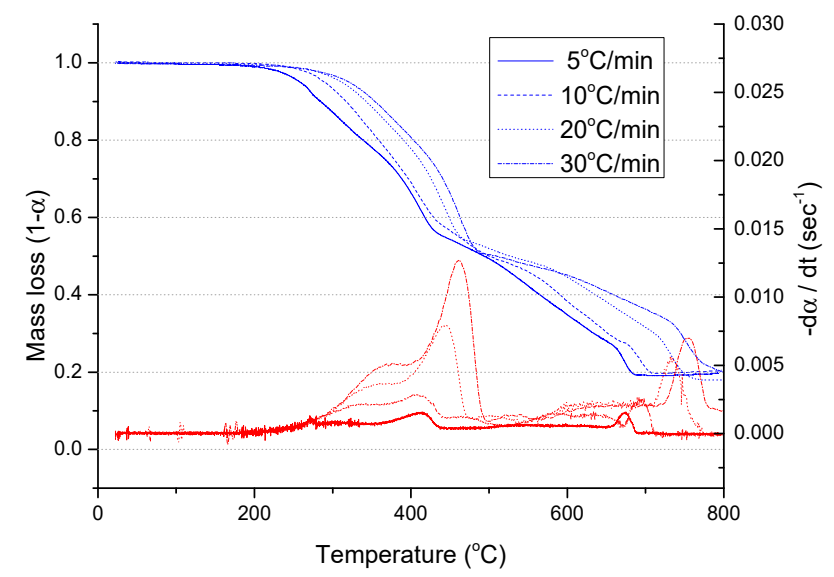

(d)

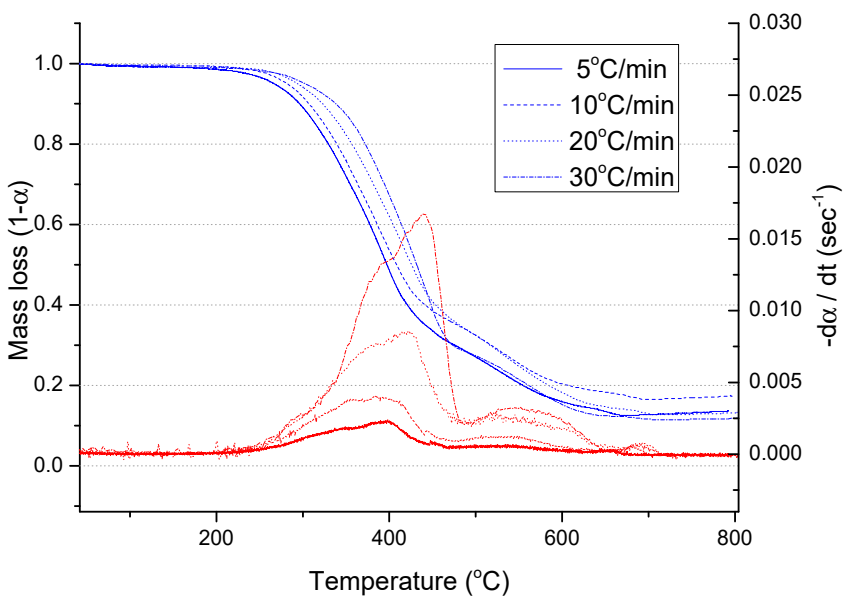

(e)

Figure 1. Sample mass loss ratio and mass change rate vs. temperature for (a) sponge foam, (b) plastic, (c) fiber, (d) rubber, and (e) mixed ASR. 
The mass loss and the rate of change of each sample under the temperature rise rate of $20^{\circ} \mathrm{C}$ are shown in a graph in Figure 2. The temperature range according to the change in the mass loss of the samples can be divided into four stages: section I between about 250 and $395^{\circ} \mathrm{C}$; section II between 400 and $480^{\circ} \mathrm{C}$; section III between 480 and $630^{\circ} \mathrm{C}$; and section IV between 630 and $750{ }^{\circ} \mathrm{C}$. Figure 2 shows four materials mass decomposition of sponge foam, plastic and fiber including mixed samples, gradually occurred around $250{ }^{\circ} \mathrm{C}$, and indicates that the mass reduction was completed near $630^{\circ} \mathrm{C}$ which is the end of section III. Foams and plastics containing a large amount of volatile substances showed the largest mass loss in the first section, and most of the mass loss occurred near section $480^{\circ} \mathrm{C}$ in section II. Compared to foam and plastic, fiber and rubber showed a moderate mass loss due to temperature rise, and showed a mass loss peak over three sections. Fiber showed mass loss rate peaks over sections I, II, and III, and rubber showed mass loss rate peaks over sections I and II, and sections III and IV, with high mass loss peaks around $750{ }^{\circ} \mathrm{C}$. This means that fiber and rubber contain more polymer compounds than foam and plastic, and the final mass is reduced when rubber is over $750^{\circ} \mathrm{C}$. In the mixed sample, the shape of the mass loss graph is very similar to that of the fiber, and the maximum mass loss peak is also shown near $450^{\circ} \mathrm{C}$. Finally, the mass loss was completed at around $725^{\circ} \mathrm{C}$. The effect of rubber shows a little mass reduction peak near $725^{\circ} \mathrm{C}$, and the final decomposition temperature in the mixed sample was slightly lowered from $750{ }^{\circ} \mathrm{C}$ of rubber to $725^{\circ} \mathrm{C}$. L. Sørum et al. (2001), in their MSW (municipal solid waste) pyrolysis studies showed that the mass loss temperature of PS, PP, LDPE (low density polyethylene), and HDPE (high density polyethylene), which dominates plastics, varied from $350{ }^{\circ} \mathrm{C}$ to $500{ }^{\circ} \mathrm{C}$, with maximum mass losses between $413^{\circ} \mathrm{C}$ and $479{ }^{\circ} \mathrm{C}$. On the other hand, PVC has two stages of thermal loss and occurred between $200-380^{\circ} \mathrm{C}$ and $400-500^{\circ} \mathrm{C}$. In the first step, chlorine-rich parts are decomposed and in the next step the remaining hydrocarbons are decomposed [21]. In light of this, stages I and II in Figure 2 are similar to the PVC mass loss temperature range, and stage II represents the mass loss temperature range of the conventional plastics mentioned above. It can be estimated that the fibers and sponge foam contain chlorine-containing hydrocarbons.

\subsection{Kinetic Analysis of ASR Samples Decomposition}

The activation energy values were determined using three types of models (FWO, KAS, and Freidman) to obtain reliable kinetic parameters of five samples collected from the ASR. First, the activation energies were calculated using Equations (7)-(9). Using the FWO model, KAS model and Friedman model, the sample mass conversion ratio $(\alpha)$ of the samples was calculated by selecting from 0.1 to 0.8 . Figure 3 shows the kinetic plots of the mixed ASR samples for each conversion ratio and shows good agreement with the experimental data. The activation energies $(E)$ from the slopes of each straight line and the corresponding correlation coefficients $\left(r^{2}\right)$ for the plots were calculated, and are shown in Table 2 . The mean activation energy values were within $5 \%$ of all other samples except for the sponge foam sample. In sponge foam, the average activation energy value obtained by Friedman's model compared to other FWO and KAS models was 19\% higher. Activation energy is clearly influenced by experimental instruments, processes, and models that are calculated in not only this study but also other studies. In L. Sørum et al. (2001)'s study, PS, PP, LDPE, HDPE and PVC each has $311.5 \mathrm{~kJ} / \mathrm{mol}, 336.7 \mathrm{~kJ} / \mathrm{mol}, 340.8 \mathrm{~kJ} / \mathrm{mol}, 445.1 \mathrm{~kJ} / \mathrm{mol}$ and $110-388 \mathrm{~kJ} / \mathrm{mol}$ activation energy [21]. These energy value is related the bonding energies of $\mathrm{C}-\mathrm{C}, \mathrm{C}-\mathrm{H}, \mathrm{C}=\mathrm{C}$ and $\mathrm{C}-\mathrm{Cl}$ of the hydrocarbon compounds, $347 \mathrm{~kJ} / \mathrm{mol}, 414 \mathrm{~kJ} / \mathrm{mol}, 611 \mathrm{~kJ} / \mathrm{mol}$, and 140-390 kJ/mol respectively. Poong Mo Park et al. (2017) said the activation energy of waste PP and PE were $75.67 \mathrm{~kJ} / \mathrm{mol}$ and $134.80 \mathrm{~kJ} / \mathrm{mol}$ respectively. Since PE is more stable than PP, it requires more energy for thermal decomposition [32]. In another study, the activation energies of RDF (refuse derived fuel) with a mixture of various wastes and a fiber content of more than $65 \%$, were $135.6 \mathrm{~kJ} / \mathrm{mol}$ for $\alpha=0.1$ and $153 \mathrm{~kJ} / \mathrm{mol}$ for $\alpha=0.2-0.7$. As mentioned above, the activation energy varies slightly depending on the experiment and calculations. However, these thermal properties can be used to infer the approximate composition of the material. 
Figure 4 shows the activation energy from each model as mass conversion increases. the sample mass conversion rate range 0.1 to 0.8 for each sample: (a) sponge foam; (b) plastic; (c) rubber; (d) fiber; and (e) mixed sample, the mean energy values are shown in bar graphs. The activation energy values calculated from the FWO and KAS models show nearly identical patterns throughout the mass conversion rate. On the other hand, the activation energy value calculated in the Friedman model is very different from that of FWO and KAS models. Sponge foams (a) and rubber (c) decrease the activation energy from the mass conversion rates of 0.7 and 0.6 , respectively, as the mass conversion rate increases, but in other samples, the activation energy value increases as the mass conversion rate increases. In the mixed sample (e), the patterns of activation energy graphs of the other different samples appeared to be complex. In particular, the graph of the Friedman model was lower than that of the FWO and KAS models after the conversion rate of 0.6 due to the effects of the above rubber and fiber. The activation energies of plastics and rubbers were $105.39 \mathrm{~kJ} / \mathrm{mol}$ and $115.20 \mathrm{~kJ} / \mathrm{mol}$, respectively. The sponge foams and fibers were $172.59 \mathrm{~kJ} / \mathrm{mol}$ and $160.30 \mathrm{~kJ} / \mathrm{mol}$, respectively. The mixed sample, in which the four samples were mixed in proportion, had an activation energy value of $159.56 \mathrm{~kJ} / \mathrm{mol}$, which was almost similar to that of the fiber.

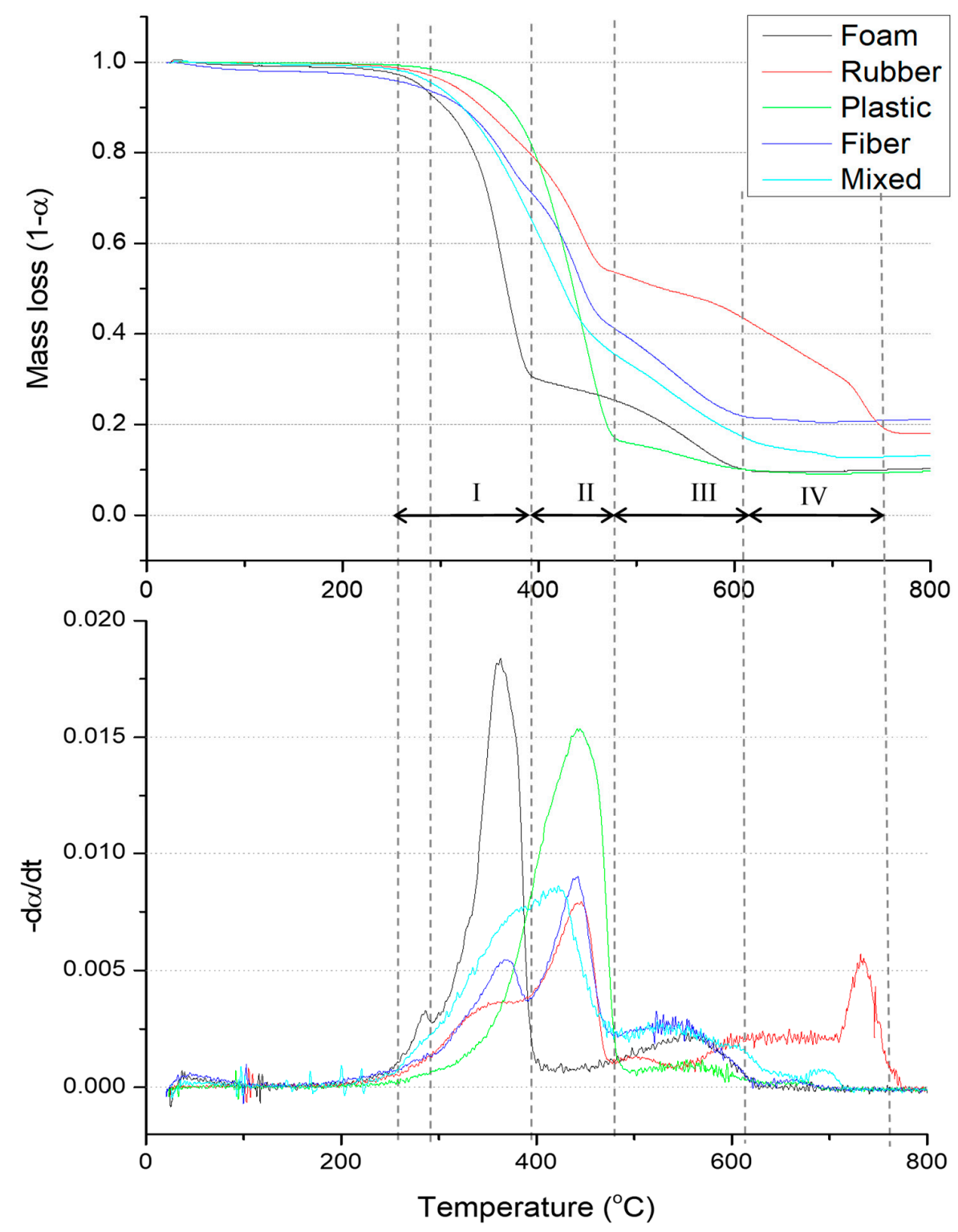

Figure 2. Sample mass loss ratio and mass change rate vs. temperature at $20^{\circ} \mathrm{C} / \mathrm{min}$ heating rate. 


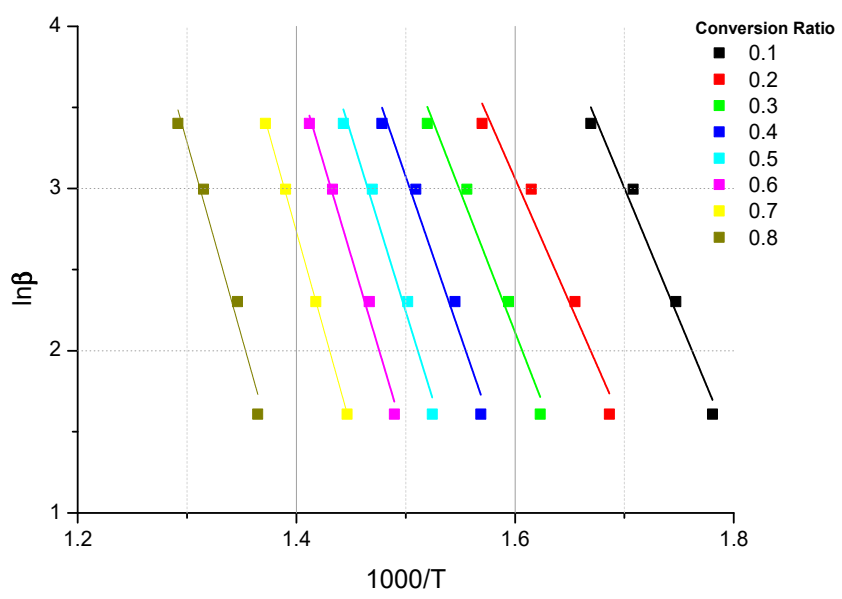

(a)

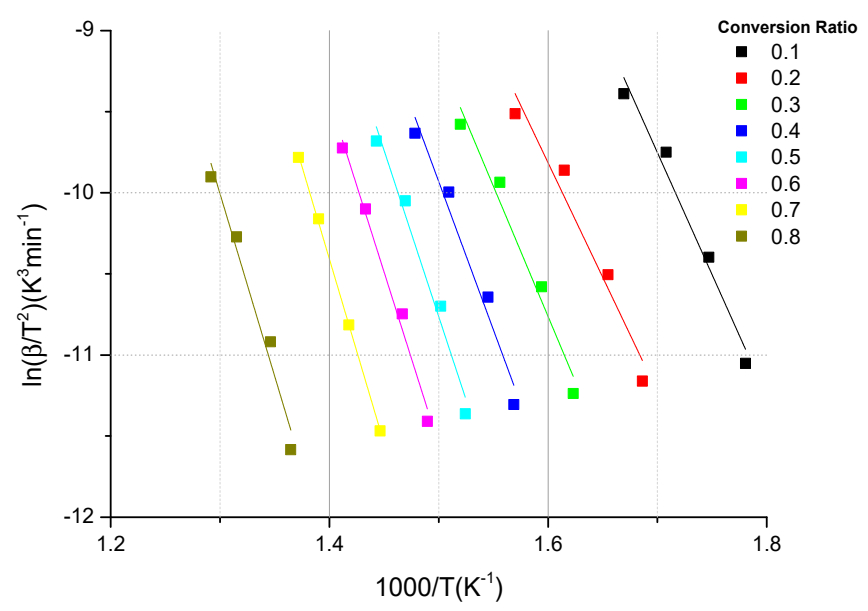

(b)

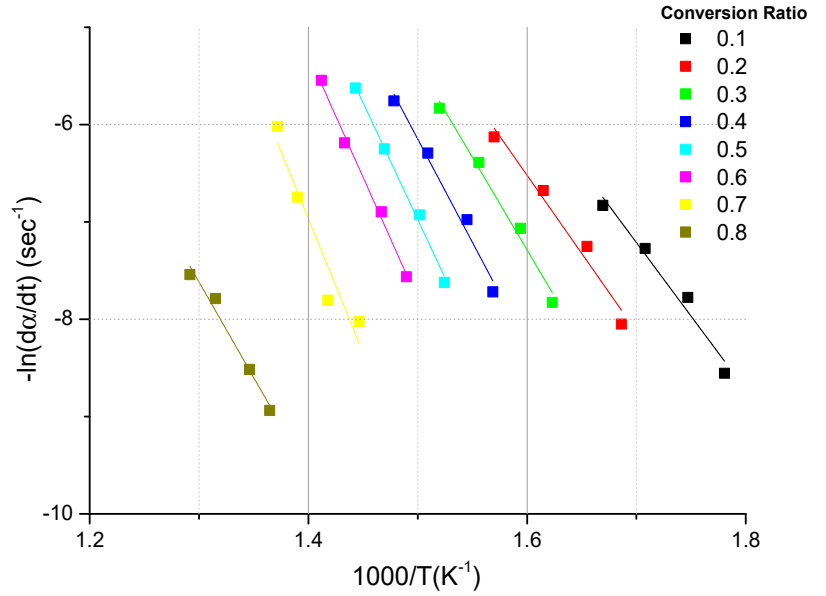

(c)

Figure 3. Plots for kinetic models for Mixed ASR. (a) Flynn-Wall-Ozawa (FWO), (b) Kissinger-AkahiraSunose (KAS), (c) Friedman. 
Table 2. Calculated kinetic parameter, $r^{2}$ values and $E(\mathrm{~kJ} / \mathrm{mol})$ of the fitted equation from FWO, KAS and Friedman models.

\begin{tabular}{|c|c|c|c|c|c|c|c|}
\hline & \multirow{2}{*}{$\begin{array}{c}\text { Conversion } \\
\text { Ratio }\end{array}$} & \multicolumn{2}{|c|}{ Friedman Approach } & \multicolumn{2}{|c|}{ KAS Approach } & \multicolumn{2}{|c|}{ FWO Approach } \\
\hline & & $r^{2}$ & $E(\mathrm{~kJ} / \mathrm{mol})$ & $r^{2}$ & $E(\mathrm{~kJ} / \mathrm{mol})$ & $r^{2}$ & $E(\mathrm{~kJ} / \mathrm{mol})$ \\
\hline \multirow{9}{*}{ Sponge foam } & 0.1 & 0.98 & 90.10 & 0.93 & 89.92 & 0.95 & 94.47 \\
\hline & 0.2 & 0.95 & 162.34 & 0.95 & 105.89 & 0.96 & 110.14 \\
\hline & 0.3 & 0.88 & 201.65 & 0.86 & 140.70 & 0.88 & 143.54 \\
\hline & 0.4 & 0.80 & 247.58 & 0.88 & 177.15 & 0.89 & 178.41 \\
\hline & 0.5 & 0.72 & 218.79 & 0.75 & 189.52 & 0.77 & 190.34 \\
\hline & 0.6 & 0.83 & 216.70 & 0.79 & 202.70 & 0.81 & 202.98 \\
\hline & 0.7 & 0.95 & 209.12 & 0.86 & 204.40 & 0.87 & 204.70 \\
\hline & 0.8 & 0.90 & 188.62 & 0.95 & 183.64 & 0.96 & 185.10 \\
\hline & Average & & 192.32 & & 161.74 & & 163.71 \\
\hline \multirow{9}{*}{ Plastic } & 0.1 & 0.98 & 88.72 & 0.87 & 69.58 & 0.90 & 75.98 \\
\hline & 0.2 & 0.99 & 101.55 & 0.91 & 75.34 & 0.93 & 81.88 \\
\hline & 0.3 & 0.99 & 111.82 & 0.97 & 89.32 & 0.98 & 95.41 \\
\hline & 0.4 & 0.99 & 116.83 & 1.00 & 99.84 & 0.99 & 105.60 \\
\hline & 0.5 & 0.95 & 120.55 & 0.99 & 103.22 & 0.99 & 108.99 \\
\hline & 0.6 & 0.98 & 127.46 & 0.99 & 109.40 & 0.99 & 115.03 \\
\hline & 0.7 & 0.98 & 131.33 & 0.99 & 113.06 & 0.99 & 118.67 \\
\hline & 0.8 & 0.98 & 124.99 & 0.99 & 119.65 & 0.99 & 125.10 \\
\hline & Average & & 115.41 & & 97.43 & & 103.33 \\
\hline \multirow{9}{*}{ Rubber } & 0.1 & 0.98 & 67.46 & 0.97 & 61.95 & 0.98 & 68.05 \\
\hline & 0.2 & 0.99 & 80.45 & 1.00 & 77.45 & 0.99 & 83.62 \\
\hline & 0.3 & 0.98 & 99.53 & 0.98 & 96.11 & 0.99 & 101.82 \\
\hline & 0.4 & 0.97 & 149.87 & 0.96 & 121.17 & 0.97 & 126.11 \\
\hline & 0.5 & 0.99 & 200.14 & 0.96 & 155.12 & 0.96 & 158.71 \\
\hline & 0.6 & 0.94 & 119.33 & 0.99 & 160.65 & 0.99 & 164.90 \\
\hline & 0.7 & 0.87 & 91.55 & 0.99 & 123.21 & 0.99 & 130.51 \\
\hline & 0.8 & 0.96 & 111.79 & 0.96 & 104.43 & 0.97 & 110.74 \\
\hline & Average & & 115.02 & & 112.51 & & 118.06 \\
\hline \multirow{9}{*}{ Fiber } & 0.1 & 0.98 & 131.42 & 0.99 & 120.67 & 0.99 & 123.71 \\
\hline & 0.2 & 0.97 & 132.20 & 0.95 & 140.51 & 0.95 & 143.29 \\
\hline & 0.3 & 0.99 & 144.26 & 0.97 & 143.07 & 0.97 & 146.10 \\
\hline & 0.4 & 0.98 & 177.89 & 0.96 & 160.20 & 0.97 & 162.82 \\
\hline & 0.5 & 0.99 & 155.04 & 0.96 & 174.57 & 0.97 & 176.80 \\
\hline & 0.6 & 0.99 & 149.65 & 0.97 & 182.29 & 0.98 & 184.38 \\
\hline & 0.7 & 0.91 & 163.77 & 0.99 & 181.13 & 0.99 & 183.52 \\
\hline & 0.8 & 0.73 & 159.40 & 0.89 & 204.35 & 0.90 & 206.22 \\
\hline & Average & & 151.70 & & 163.35 & & 165.86 \\
\hline \multirow{9}{*}{$\begin{array}{c}\text { Mixed } \\
\text { samples }\end{array}$} & 0.1 & 0.96 & 125.75 & 0.97 & 125.10 & 0.97 & 128.08 \\
\hline & 0.2 & 0.96 & 133.53 & 0.94 & 117.49 & 0.95 & 121.40 \\
\hline & 0.3 & 0.98 & 158.22 & 0.96 & 133.48 & 0.96 & 136.95 \\
\hline & 0.4 & 0.97 & 176.37 & 0.96 & 151.90 & 0.96 & 154.77 \\
\hline & 0.5 & 0.99 & 199.61 & 0.97 & 170.44 & 0.97 & 172.67 \\
\hline & 0.6 & 0.99 & 163.79 & 0.98 & 177.10 & 0.99 & 179.24 \\
\hline & 0.7 & 0.89 & 166.13 & 1.00 & 189.05 & 0.99 & 190.93 \\
\hline & 0.8 & 0.97 & 180.70 & 0.96 & 187.07 & 0.96 & 189.73 \\
\hline & Average & & 163.01 & & 156.45 & & 159.22 \\
\hline
\end{tabular}




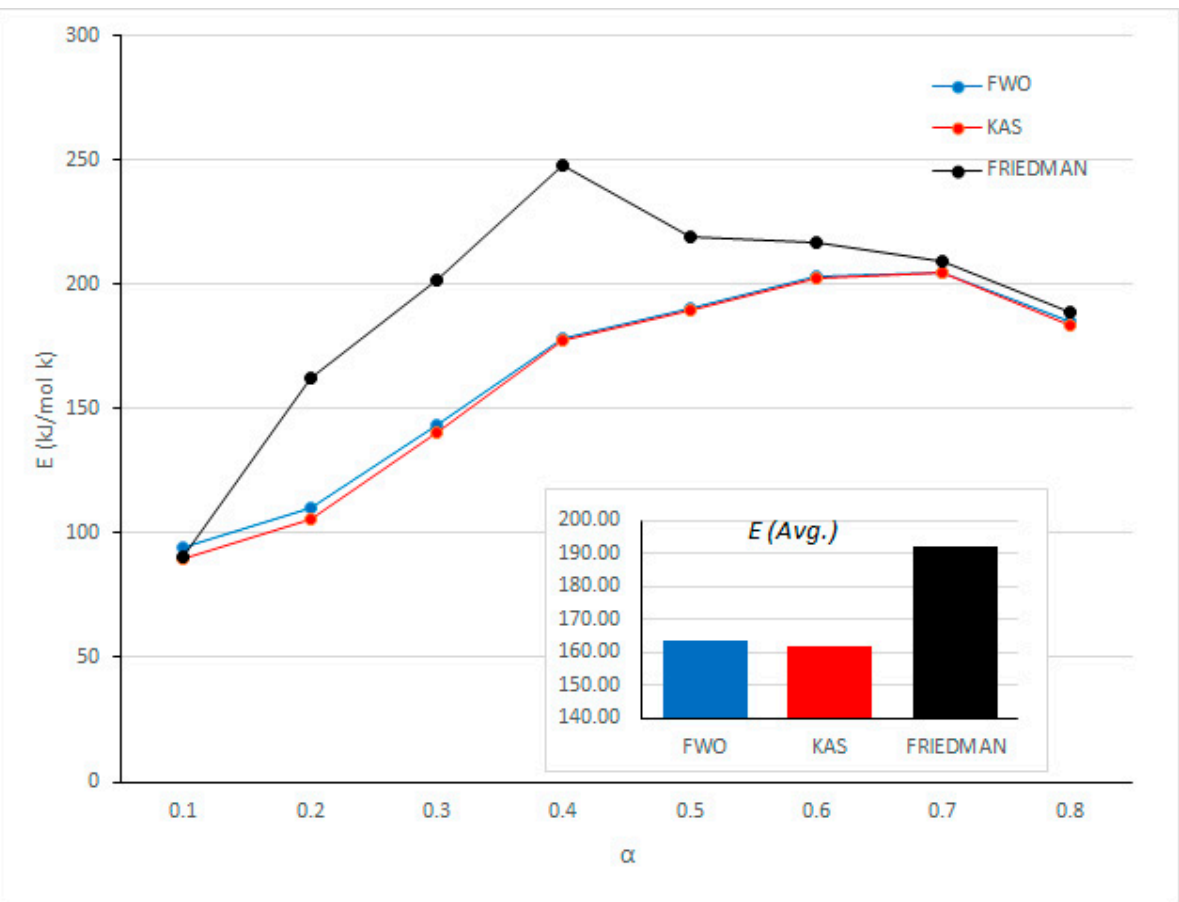

(a)

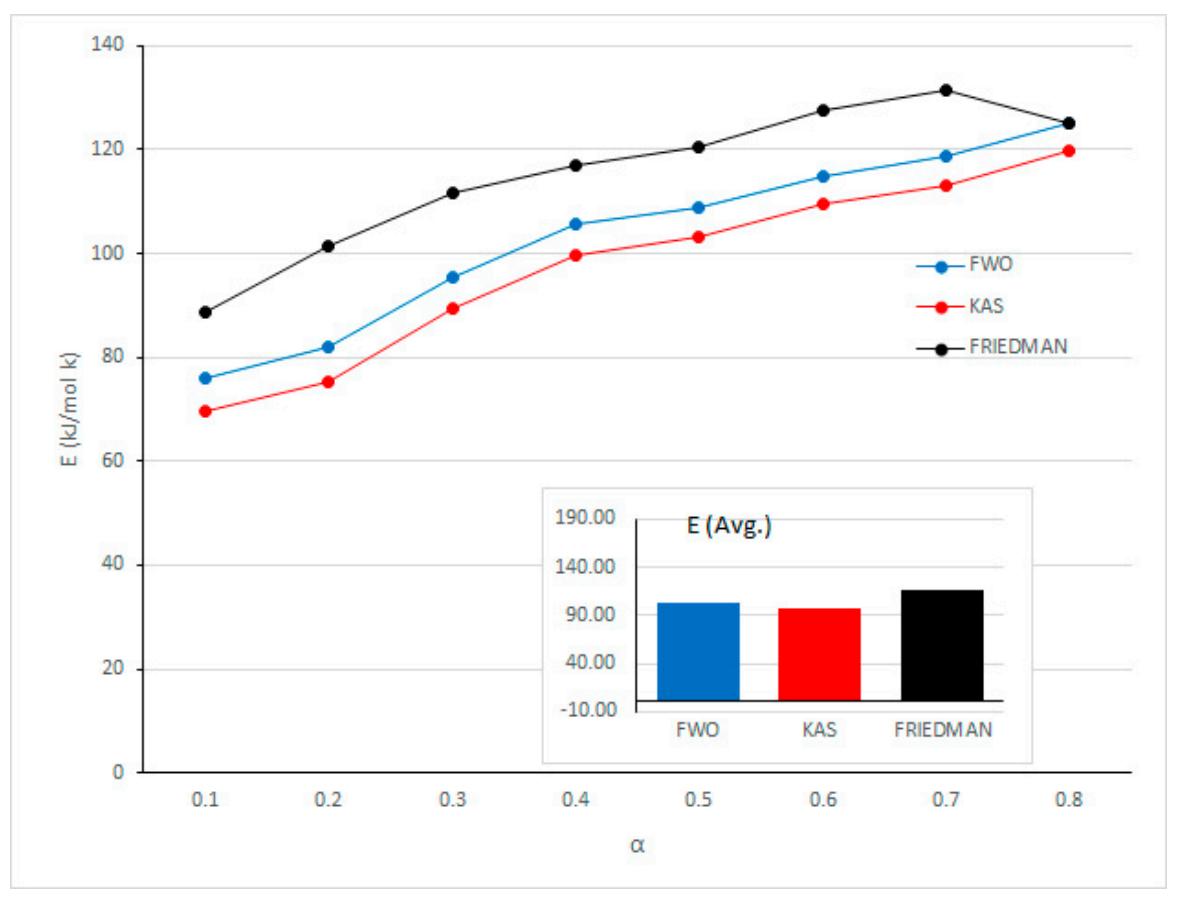

(b)

Figure 4. Cont. 


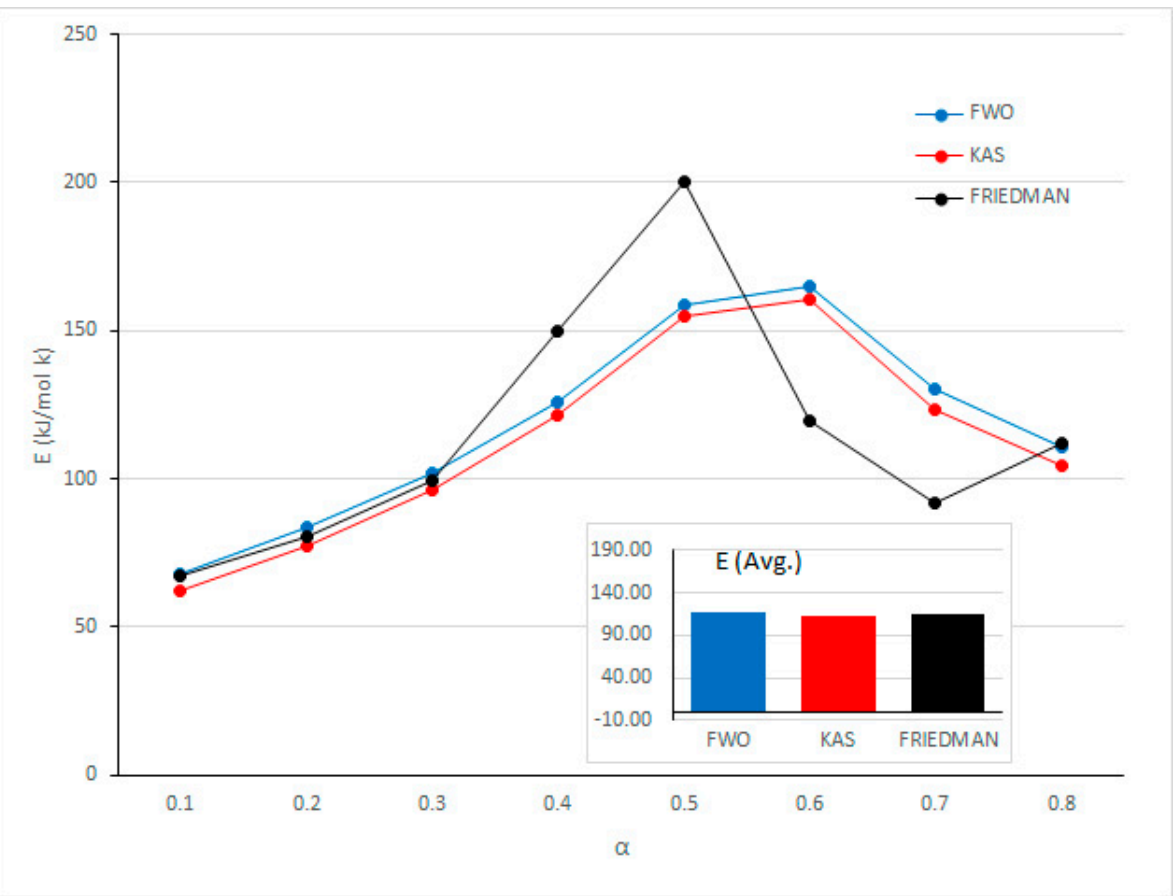

(c)

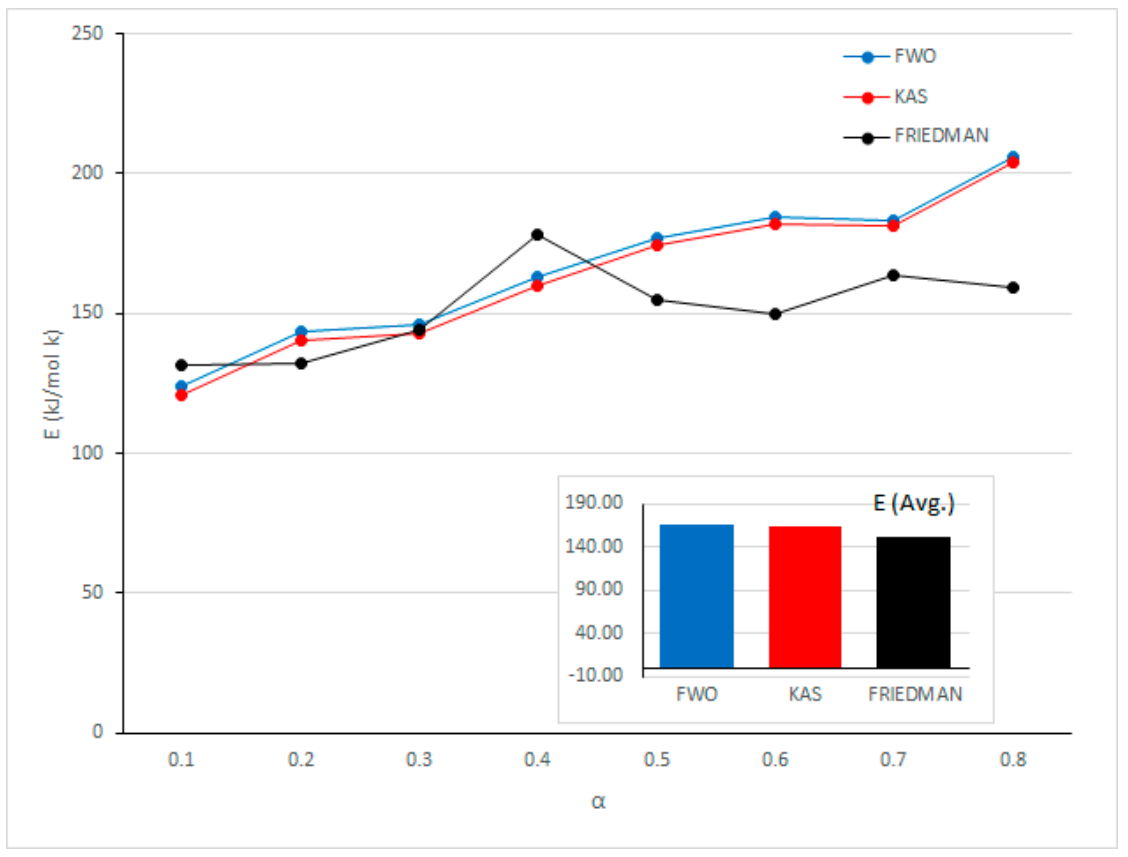

(d)

Figure 4. Cont. 


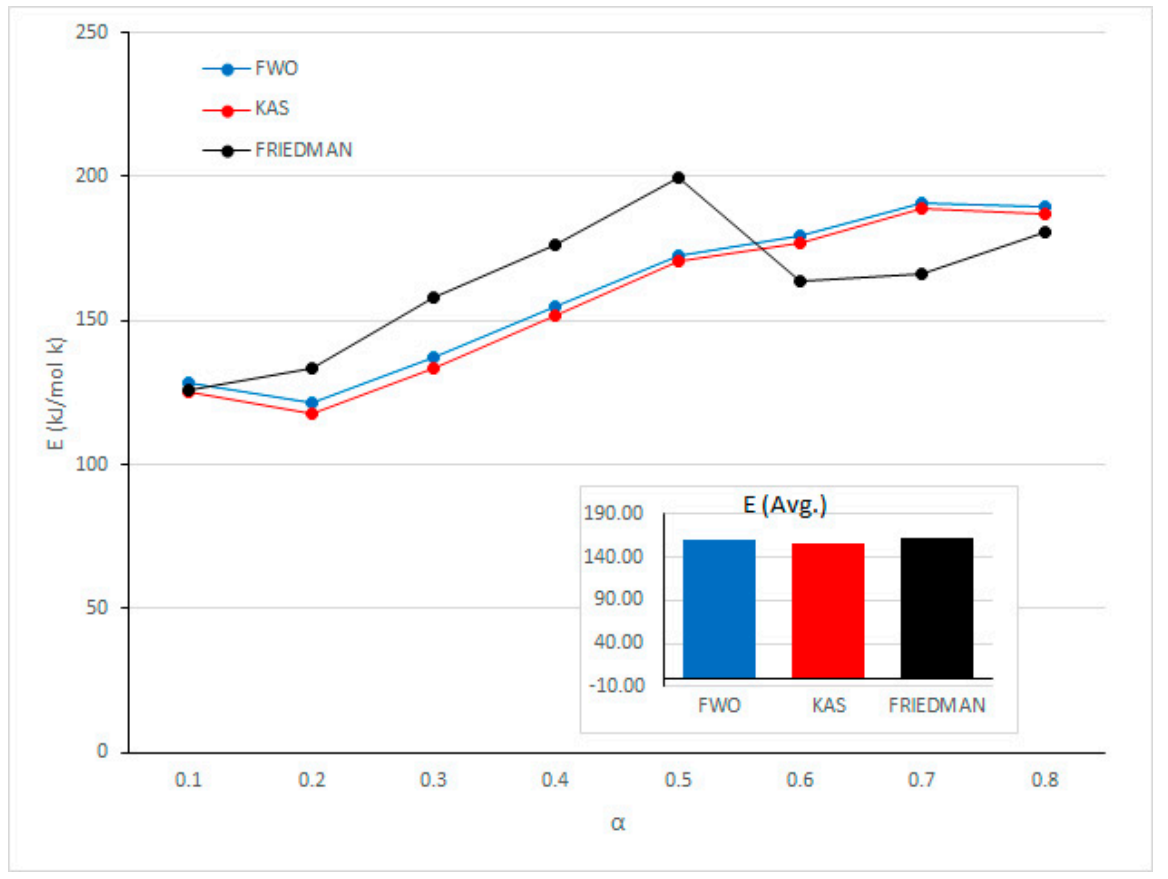

(e)

Figure 4. Comparison of activation energy values $(E, \mathrm{~kJ} / \mathrm{mol})$ vs. conversion ration obtained by different isoconversional model methods. (a) sponge foam, (b) plastic, (c) rubber, (d) fiber, (e) mixed sample.

\section{Conclusions}

In this study, pyrolysis kinetics analysis was carried out using the TGA-DTG technique with waste car residues, automobile shredded residue (ASR), and important kinetic information such as activation energy were calculated by differential and integral isoconversional model methods. Thermogravimetric analysis was performed under nitrogen with four temperature rate conditions from room temperature to $800{ }^{\circ} \mathrm{C}$.

Four types of sponge foam, plastic, rubber, and fiber are collected and separated from the ASR, and then mixed in a ratio to make a mixed sample. From TGA/DTG profiles, thermal degradation of sponge foam and plastic produced a peak in a single temperature section, while rubber and fiber showed formation of three peaks in three temperature sections. This suggests that the compounds of rubber and fibers are more complex than sponge foam and plastic.

The thermal degradation profile of the mixed sample was found to have two main weight loss temperature sections, and the final weight loss was achieved at $725^{\circ} \mathrm{C}$, where was lower than the rubber weight loss temperature of $750^{\circ} \mathrm{C}$. It can be seen that there may be synergistic effects in thermal decomposition reactions compared to other individual feedstocks.

Quantitative determination of activation energy through three model methods is important information to discover the future reaction process and mechanism of the sample, respectively, and the thermal properties of individual combustibles of ASR and their mixtures could be used as important data when they roll as energy feedstock.

Author Contributions: Conceptualization, Y.-C.J. and S.H.; methodology, Y.-C.J. and S.H.; formal analysis, S.H.; investigation, S.-K.C.; resources, S.H..; data curation, S.H. and S.-K.C.; writing-original draft preparation, S.H.; writing-review and editing, Y.-S.C. and S.-K.C.; visualization, S.H.; supervision, Y.-S.C.; project administration, Y.-S.C. All authors have read and agreed to the published version of the manuscript.

Funding: This research received no external funding.

Conflicts of Interest: The authors declare no conflicts of interest. 


\section{Nomenclature}

$\begin{array}{lll}E & \text { Activation Energy } & \mathrm{kJ} / \mathrm{mol} \\ A & \text { Frequency factor } & \mathrm{s}^{-1} \\ T & \text { Temperature } & \mathrm{K} \\ R & \text { Gas Constant } & \mathrm{kJ} \cdot \mathrm{K} / \mathrm{mol} \\ X_{0} & \text { Initial Sample Mass } & \mathrm{g} \\ X_{\Gamma} & \text { Residual Sample Mass at time }{ }_{\Gamma} & \mathrm{g} \\ X_{f} & \text { Final Sample Mass } & \mathrm{g} \\ k & \text { Rate Constant } & \\ \alpha & \text { Conversion } & \\ \beta & \text { Heating rate } & { }^{\circ} \mathrm{C} / \mathrm{min} \\ t & \text { Time } & \mathrm{s}\end{array}$

\section{References}

1. Korea Ministry of Land, Infrastructure and Transport. Car Registration Status. Available online: http: //www.index.go.kr/potal/main/EachDtlPageDetail.do?idx_cd=1257 (accessed on 20 November 2019).

2. Korea Auto Dismantlement Recycling Association. Available online: http://kadra.or.kr/kadra/contents/main/ main.html (accessed on 20 November 2019).

3. Ho-suk, J. Development of Physical Separation System for Resource Recycling of ASR; Korea Ministry of Environment: Sejong City, Korea, 2016.

4. Granata, G.; Moscardini, E.; Furlani, G.; Pagnanelli, F.; Toro, L. Automobile shredded residue valorisation by hydrometallurgical metal recovery. J. Hazard. Mater. 2011, 185, 44-48. [CrossRef] [PubMed]

5. Kuwayama, Y.; Ito, M.; Hiroyoshi, N.; Tsunekawa, M. Jig separation of crushed automobile shredded residue and its evaluation by float and sink analysis. J. Mater. Cycles Waste Manag. 2011, 13, 240-246. [CrossRef]

6. Di Palma, L.; Medici, F.; Vilardi, G. Artificial aggregate from non-metallic automotive shredder residue. Chem. Eng. Trans. 2015, 43, 1723-1728.

7. Lee, H.Y.; Oh, J.K. A study on the shredding of end-of-life vehicles and materials separation. Geosyst. Eng. (KSGM) 2003, 6, 100-105. [CrossRef]

8. Allen, T.; Anew, E. Benefits of holistic shredder residue recovery: Mechanical recycling and energy recovery. In Proceedings of the International Thermal Treatment Technologies (IT3) and Hazardous Waste Combustors (HWC) Joint Conference 2009, Cincinnati, OH, USA, 18-21 May 2009; pp. 484-491.

9. Ujsághy, Z. Recycling methods of car wreck residues. In Proceedings of the Mini Conference on Vehicle System Dynamics, Identification and Anomalies; Technical University of Budapest: Budapest, Hungary, 2008; pp. 483-489.

10. Bezergianni, S.; Dimitriadis, A.; Faussone, G.C.; Karonis, D. Alternative diesel from waste plastics. Energies 2017, 10, 1750. [CrossRef]

11. Zolezzi, M.; Nicolella, C.; Ferrara, S.; Iacobucci, C.; Rovatti, M. Conventional and fast pyrolysis of automobile shredder residues (ASR). Waste Manag. 2004, 24, 691-699. [CrossRef]

12. Tomita, Y.; Takasuka, G.; Sugimoto, T.; Itaya, M. Treatment of Automobile Shredded Residue by Kiln-type Pyrolysis and Melting Process. Proc. Symp. Environ. Eng. 2001, 11, 246-249. [CrossRef]

13. Roh, S.A.; Kim, W.H.; Yun, J.H.; Min, T.J.; Kwak, Y.H.; Seo, Y.C. Pyrolysis and gasification-melting of automobile shredder residue. J. Air Waste Manag. 2013, 63, 1137-1147. [CrossRef]

14. Yatsun, A.V.; Konovalov, N.P.; Efimenko, I.S. Liquid products of the microwave pyrolysis of scrap tires. Solid Fuel Chem. 2013, 47, 252-254. [CrossRef]

15. Day, M.; Cooney, D.; Mackinnon, M. Degradation of contaminated plastics: A kinetic study. Polyim. Degrad. Stab. 1995, 48, 341-349. [CrossRef]

16. Donaji, P.; Yang, W.; Blasiak, W. Kinetic study of decomposition of ASR residues after pyrolysis in inert and oxidative atmospheres. In Proceedings of the International Thermal Treatment Technologies (IT3) \& Hazardous Waste Combustors (HWC) Joint Conference 2009, Cincinnati, OH, USA, 18-21 May 2009; pp. $465-483$.

17. Haydary, J.; Susa, D.; Gelinger, V.; Čacho, F. Pyrolysis of automobile shredder residue in a laboratory scale screw type reactor. J. Environ. Chem. Eng. 2016, 4, 965-972. [CrossRef] 
18. Mayyas, M.; Pahlevani, F.; Handoko, W.; Sahajwalla, V. Preliminary investigation on the thermal conversion of automotive shredder residue into value-added products: Graphitic carbon and nano-ceramics. Waste Manag. 2016, 50, 173-183. [CrossRef]

19. Srogi, K. An overview of current processes for the thermochemical treatment of automobile shredder residue. Clean Technol. Environ. 2008, 10, 235-244. [CrossRef]

20. Sun, J.; Wang, W.; Liu, Z.; Ma, Q.; Zhao, C.; Ma, C. Kinetic study of the pyrolysis of waste printed circuit boards subject to conventional and microwave heating. Energies 2012, 5, 3295-3306. [CrossRef]

21. Sørum, L.; Gronli, M.G.; Hustad, J.E. Pyrolysis characteristics and kinetics of municipal solid wastes. Fuel 2001, 80, 1217-1227. [CrossRef]

22. Mohammed, I.Y.; Abakr, Y.A.; Kazi, F.K.; Yusup, S.; Alshareef, I.; Chin, S.A. Comprehensive characterization of Napier grass as a feedstock for thermochemical conversion. Energies 2015, 8, 3403-3417. [CrossRef]

23. Vyazovkin, S.; Wight, C. Model-free and model-fitting approaches to kinetic analysis of isothermal and non-isothermal data. Thermochim. Acta 1999, 340-341, 53-68. [CrossRef]

24. Friedman, H.L. Kinetics of thermal degradation of char-forming plastics from thermogravimetry. Application to a phenolic plastic. J. Polym. Sci. Polym. Symp. 2007, 6, 183-195. [CrossRef]

25. Ozawa, T. A New Method of Analyzing Thermogravimetric Data. Bull. Chem. Soc. Jpn. 1965, 38, 1881-1886. [CrossRef]

26. Doyle, C.D. Kinetic analysis of thermogravimetric data. J. Appl. Polym. 1961, 5, 285-292. [CrossRef]

27. Apaydin, V.E.; Polat, S.; Putun, A.E. Pyrolysis kinetics and thermal decomposition behavior of polycarbonate-A TGA-FTIR study. Therm. Sci. 2014, 18, 833-842. [CrossRef]

28. Kissinger, H.E. Reaction Kinetics in Differential Thermal Analysis. Anal. Chem. 1957, 29, $1702-1706$. [CrossRef]

29. Milos, R.; Martina, B.; Vladimir, J.; Dragoslava, S.; Nebojsa, M. Thermogravimetric kinetic study of solid recovered fuels pyrolysis. Hem. Ind. 2018, 72, 99-106.

30. Joung, H.T.; Seo, Y.C.; Kim, K.H.; Hong, J.H.; Yoo, T.W. Distribution and characteristics of pyrolysis products from automobile shredder residue using an experimental semi-batch reactor. Korean J. Chem. Eng. 2007, 24, 996-1002. [CrossRef]

31. Chao-Hsiung, W. On the thermal treatment of plastic mixtures of MSW: Pyrolysis kinetics. Waste Manag. 1993, 13, 221-235. [CrossRef]

32. Park, P.M.; Yeo, S.G.; Hyun, S.M.; Yoon, J.R.; Dong, J.I. Thermogravimetric analysis and kinetic studies of biomass mixed with waste plastic. J. Korea Soc. Waste Manag. 2018, 35, 72-83. [CrossRef] 